\title{
Some characteristics of people's traumatic memories
}

\author{
SVEN-ÅKE CHRISTIANSON \\ University of Stockholm, Stockholm, Sweden \\ and \\ ELIZABETH F. LOFTUS \\ University of Washington, Seattle, Washington
}

\begin{abstract}
In this study, we examined whether highly emotional events are associated with persistence of memory for both central and peripheral detail, as has been claimed elsewhere in the literature (e.g., Yuille \& Cutshall, 1989). A total of 437 subjects in two experiments were asked to report their "most traumatic memory" and to answer questions about their chosen memory. A major finding was a significant relationship between rated degree of emotion and the number of central details, but not peripheral details, the subjects believed that they remembered. The implication of this result for the study of emotional memory is discussed.
\end{abstract}

What do people retain from traumatic events? A popular scientific approach to this problem is the simulation study, wherein subjects witness a laboratory-induced emotionally arousing event and are then asked to remember details about it. In various studies using this approach, subjects have witnessed simulated assaults (Clifford \& Hollin, 1981; Clifford \& Scott, 1978), simulated accidents (Christianson, 1984; Christianson \& Loftus, 1987, 1989; Christianson, Loftus, Loftus, \& Hoffman, 1989; Heuer, 1987), and simulated shootings (Loftus \& Burns, 1982). However, these laboratory simulations seem pale when compared to the kinds of real-life trauma that we regularly read about in newspapers. While we can appreciate that witnessing a genuine accident would be far more emotionally arousing or traumatizing than witnessing a simulated accident in a laboratory, can we assume that we cannot learn about emotional memories from laboratory settings? According to Yuille and Cutshall (1989), we cannot. Yuille and Cutshall claim that witnessing real crimes leads to "qualitatively different memories than the innocuous laboratory events"' (p. 178).

To study memory for emotional events, Yuille and Cutshall (1989) adopted a different approach. They sought witnesses to actual traumatic events (e.g., shootings, knifings) and interviewed those witnesses extensively. What they found were "remarkable memories" characterized

This research was supported by Grant F. 194/88 from the Swedish Council for Research in the Humanities and Social Sciences to SvenẢke Christianson, and by a grant from the National Institute of Mental Health to Elizabeth Loftus. This research was conducted while the first author was a visiting scholar at the University of Washington, on fellowship awards from the Fulbright Commission and from the Swedish Institute. The authors are indebted to Hunter Hoffman for his help in conducting this research. Correspondence may be addressed to SvenẢke Christianson, Department of Psychology, University of Stockholm, S-10691 Stockholm, Sweden. as being "detailed, accurate, and persistent" (p. 181). Is this a correct view of emotional memories? According to many laboratory studies, the picture is more complex. Some studies (e.g., Clifford \& Scott, 1978) have reported worse memory for details in emotional compared to neutral events, without noting whether the details being examined were central or peripheral. Other studies (e.g., Heuer, 1987) have shown the opposite result. Still others (e.g., Christianson \& Loftus, 1987, 1989) have shown good memory for central details of emotional versus neutral events, but impaired memory for peripheral details, or details surrounding the emotion-eliciting event.

These considerations prompted us to examine memory for naturally occurring emotional events. In our research, subjects rated their most traumatic memories on a variety of scales, and estimated the number of central and peripheral details that they thought they remembered about their chosen event. Our main interest was in whether highly emotional events are associated with persistence of detail, both central and peripheral, as Yuille and Cutshall would have us believe. Similar claims have been made in some studies of so-called "flashbulb memories," where the idea was popularized that the brain "takes a picture" of the event, and the individual remembers the exact surroundings in exceptional detail (see Brown \& Kulik, 1977).

A secondary interest in this research was to learn more about truly traumatic memories. The flashbulb studies, for example, tell us primarily about one small class of traumatic memories-namely, memories for public or national events such as political assassinations (e.g., Brown \& Kulik, 1977; Christianson, 1989; Winograd \& Killinger, 1983). But these are only a small class of traumatic memories for people. When Rubin and Kozin (1984) asked subjects to provide particularly vivid memories, only a small fraction (less than 3\%) fit the "newsworthy event 
category"' (p. 87). Thus, these newsworthy events are not the ones that are likely to be given to the request to supply one's "most traumatic event." Instead of taking a single emotional event (e.g., a shooting) and assuming that it was particularly traumatic for all involved, we asked subjects to tell us about their individual "most traumatic memory," and then to provide further information about it. For example, subjects told us when it happened, how often they discussed it, and whether some details stood out in their memories as being especially vivid or salient.

\section{EXPERIMENT 1}

\section{Method}

The subjects were 229 students at the University of Washington who filled out a questionnaire as part of a course requirement (identity was optional). The subjects were instructed: "If possible, think of the most traumatic event you have experienced in your life. By traumatic event, we mean an extremely sudden and disturbing event that overwhelmed you with shockingly negative emotional feelings." Then they answered six questions about their chosen memory:

1. In general, how vivid is your overall memory for this event? ( 1 = vague; 11 = extremely vivid. $)$

2. How many central details do you remember which are relevant and directly associated with the traumatic event per se? $(1=$ few; 2 = many; 3 = almost all.)

3. How many peripheral details do you remember from this eventdetails which were not necessarily relevant or not directly associated with the traumatic event per se? $(1=$ few; $2=$ many; $3=$ almost all. $)$

4 . How strong was your emotional feeling when you originally experienced this event? $(1=$ mildly unpleasant; $11=$ extremely unpleasant.)

5. How strong is your present emotional feeling for this experience, that is, at this moment? $(1=$ mildly unpleasant; $11=$ extremely unpleasant.)

6. If you are willing, in one sentence please describe what type of event it was (optional).

The entire questionnaire took approximately $5 \mathrm{~min}$ to complete and could be completed anonymously if the subject so wished.

\section{Results and Discussion}

The subjects recalled a variety of traumatic events. There were a number of common themes to the collection of most traumatic memories. Some common memories were: death of a relative $(12 \%)$, divorce of parents or close friend (9\%), and traffic accidents $(9 \%)$. Eleven percent of the memories concerned injury or accident involving a relative or a friend (about half of these concerned the death of a friend). Another category (15\%) was incidents involving psychological stress without accompanying physical injury or threat; for example, discovery of unfaithfulness, arrest, or a fight between parents. Incidents of a more physical character (e.g., skiing accident, broken arm, appendix operation) accounted for $3 \%$ of the memories. Another category involved miscellaneous traumatic memories, such as shootings, sexual assault, dead bodies, and so forth (6\%). The remaining $35 \%$ were not described by the subjects.

The subjects' mean ratings indicated that their most traumatic memories were relatively vivid (8.81, $S D=2.29$ ). The emotional feeling that they originally experienced at the time of the event was high (9.57,
$S D=1.84$ ), especially when compared with their present emotional feeling for the event $(5.72, S D=3.13)$. A $t$ test comparing these means was significant $[t(228)=$ $19.35, p<.001]$.

With respect to memory for details, the subjects thought they remembered more central than peripheral details. On a 3-point scale, the mean score for central details was 2.36, and for peripheral details, $1.85[t(228)=10.18$, $p<.001]$.

The correlations between the scales are shown in Table 1 . As can be seen, there is a relationship between experienced emotion and number of central details that people think they remember $(r=0.36, p<.001$, for original emotion, and $r=0.25, p<.001$, for present emotion), but not for number of peripheral details remembered. Put another way, the more intense the emotional feeling, the more central or relevant details, but not peripheral details, the subjects think they retained. This finding challenges the claim that increased emotion promotes the persistence of surrounding/peripheral details. In addition to this observation, the experiment provided little information about the nature of emotional or traumatic memories. In the second experiment, we gathered more information from subjects about when the event occurred, how often they have thought about and discussed the event, and whether there was a specific detail they remembered from the event.

\section{EXPERIMENT 2}

\section{Method}

The subjects were 208 students at the University of Washington who filled out our second questionnaire as a part of a course requirement. None of the subjects had participated in Experiment 1. The questionnaire began by asking the subjects to think of their most traumatic memory, using the same instruction as in Experiment 1. Next, the subjects were asked to rate, on an 11-point scale, how strong their emotional feeling was when they originally experienced the event $(1=$ mildly unpleasant; 11 = extremely unpleasant). They were then asked more questions: How long ago did the event occur? How many times have they reexperienced the event in their minds (thinking or dreaming about the event)? How many times have they discussed the event with other people? Next, they were asked if there was a specific detail that they remembered much better than other details from the traumatic event. If the answer to this question was yes, they were also asked if they thought of this detail as naturally central or peripheral to the core of the traumatic event. Next, they predicted whether other people would naturally remember this specific detail if the event had happened to them. The last question asked for a description of the specific detail. This item was made optional, in order not to invade the subjects' privacy.

Table 1

Correlations Between Measures in Experiment 1

\begin{tabular}{|c|c|c|c|c|c|}
\hline & Vividness & $\begin{array}{l}\text { Central } \\
\text { Details } \\
\end{array}$ & $\begin{array}{c}\text { Peripheral } \\
\text { Details }\end{array}$ & $\begin{array}{l}\text { Original } \\
\text { Emotion } \\
\end{array}$ & $\begin{array}{c}\text { Present } \\
\text { Emotion } \\
\end{array}$ \\
\hline $\begin{array}{l}\text { Vividness } \\
\text { Central Details } \\
\text { Peripheral Details } \\
\text { Original Emotion } \\
\text { Present Emotion }\end{array}$ & 1.000 & $\begin{array}{l}.610^{*} \\
1.000\end{array}$ & $\begin{array}{c}.309 * \\
.406 * \\
1.000\end{array}$ & $\begin{array}{c}.437^{*} \\
.355^{*} \\
.154 \\
1.000\end{array}$ & $\begin{array}{l}.346^{*} \\
.255^{*} \\
.143 \\
.363^{*} \\
1.000\end{array}$ \\
\hline
\end{tabular}

${ }^{*} p<.001$. 


\section{Results and Discussion}

The subjects' most traumatic memories were associated with strong emotional feelings at the time they originally experienced the event (mean rating $=8.79, S D=2.08$ ). In response to the question about when the event occurred, only a few $(5.3 \%)$ of the traumatic experiences dated back to the preceding month. A larger proportion (26.6\%) were within the interval between 1 month and 1 year. A slightly larger proportion of traumatic experiences $(29.5 \%)$ occurred from 1 to 3 years earlier. Finally, the largest proportion (38.5\%) were experiences that were older than 3 years. Thus, about $70 \%$ of the memories dated back more than 1 year. The oldest memory in our sample was 15 years old. These findings on the age of the traumatic memories mirror Rubin and Kozin's (1984) results on the age of personal flashbulb memories. Ordinary autobiographical memories tend to be more recent (e.g., within 1 year in one study) than traumatic memories.

The subjects also recalled how many times they had thought about or talked with others about this traumatic event. The events chosen by our subjects were often thought or talked about. More than half of the subjects (54\%) claimed that they had thought about the event more than 10 times. A few (9\%) said they had never thought about the event again. The analogous figures for the question about how often the subjects talked about their traumatic experience were $38 \%$ who talked about it at least 10 times and $7 \%$ who never talked about it at all.

In response to whether there was a specific detail that they remembered much better than other details from their traumatic event, $82 \%$ of the subjects said yes. Of those individuals, $57 \%$ went on to classify the detail as naturally central to the traumatic event, and $43 \%$ classified it as peripheral. The fact that nearly half of the subjects categorized their memorable detail as peripheral was somewhat unexpected. ${ }^{1}$

On what basis were they making this categorization? One clue to the answer comes from the subsequent question, where the subjects predicted whether other people would naturally remember the specific detail if they had undergone a similar experience. There was a significant correlation $(r=0.37, p<.001)$ between these questions. In lay language, subjects who classified their most memorable specific detail as central also tended to claim that other people would remember that detail. Those who classified the detail as peripheral in general believed that other people would not be likely to remember that specific detail. Although subjects referred to this detail as peripheral, it should be noted that these details were always closely associated with the emotion-eliciting event when descriptions were provided in response to the last item in the questionnaire.

In response to the last question, where the subjects were asked to describe the specific detail, the subjects recalled a variety of traumatic events (death of a relative or a close friend, sudden separation, traffic accidents, gunpoint situations, sexual assaults, etc.). Descriptions were given by $39.9 \%$ of the subjects, and out of these, $73.5 \%$ speci- fied a detail that they remembered more vividly than all other details from the traumatic event. This detail was very concrete in $70.5 \%$ of the descriptions (e.g., "how the doors behind her were closing ... in slow motion"; "an average leather jacket"; "two large rocks"; "backs of their helmets"; "X's face just before she hit me"; "the Doberman's head and teeth"; "the first moment I stepped up to the coffin .... she wasn't wearing the wedding ring which she never took off' '). The remembered detail was actually a thought or a specific feeling in $29.5 \%$ of the descriptions (e.g., "feeling of rejection, worthlessness"; "my heart felt like it was sinking").

Other correlations between scales were calculated. There was no correlation between rated emotion and how long ago the event occurred $(r=-.03, p>.05)$. There was no correlation between rated emotion and the number of times the subject thought about the event $(r=0.14$, $p>.05$ ), or between the emotion and the number of times the subject talked about the event $(r=0.04, p>$ $.05)$. These low correlations are surprising given the commonly held view that highly emotional events would be ones that are often rehearsed. In contrast, there was no relationship between emotion and rehearsal across subjects for the traumatic memories studied here. ${ }^{2}$

\section{GENERAL DISCUSSION}

A major purpose of the present study was to test the notion that peripheral details, as well as central details, persist in emotional memories. Arguing against this notion is our finding in Experiment 1 of no correlation whatsoever between experienced emotion and peripheral detail memory. This finding challenges the view that highly emotional events promote retention of a broad spectrum of details (e.g., Brown \& Kulik, 1977; Heuer, 1987; Reisberg, Heuer, McLean, \& O'Shaughnessy, 1988; Yuille \& Cutshall, 1989). Of course, it might be that people do not think they can remember many peripheral details, but in actuality they can. This is, of course, a possibility that we cannot deny.

Although people do not think they can remember many peripheral details from an emotional event, they do think they can remember many central details when the event is emotional. Thus, the pattern of data looks different depending upon whether we are considering central or peripheral detail memory. This overall pattern mirrors that found in some laboratory studies that compared the accuracy of memory for central and peripheral details in emotional and neutral events (see Christianson, 1984; Christianson \& Loftus, 1987, 1989; Christianson et al., 1989). These studies demonstrated that high emotion can be associated with relatively accurate memory for central details, but relatively inaccurate memory for peripheral details. Again, a different pattern of data emerged depending upon whether it was a central or a peripheral detail at issue.

A somewhat surprising result from Experiment 2 was the nonsignificant relationship between emotion and rehearsal. Upon deeper analysis, this may make sense. One subject, call her Anne, recalled the death of a parent as being highly traumatic and rated it 11-top of the scale. Another subject, Susan, recalled a burglary as her most traumatic memory and rated it a 7, since she knew that other events that could have happened to her would have been more traumatic. Even if ratings differ for the two people, their respective events stand out. That is, Susan might discuss or rehearse the burglary just as often as Anne talks about the death.

The favored methods of investigating emotion and memorysimulations, field studies, and autobiographical memory studies-all contribute to our fundamental knowledge of this important topic. We have found useful points of comparison across the methodological approaches, and the present research indicates that laboratory settings do not necessarily lead to qualitatively different memories than does witnessing real- 
life events, as is sometimes claimed in the literature. The discovery of points of commonality is potentially a highly profitable way to expand our knowledge in this area.

\section{REFERENCES}

Brown, R., \& KulIK, J. (1977). Flashbulb memories. Cognition, 5, 73-99.

Christianson, S.-Ȧ. (1984). The relationship between induced emotional arousal and amnesia. Scandinavian Journal of Psychology, 25, 147-160.

Christianson, S.-À. (1989). Flashbulb memories: Special, but not so special. Memory \& Cognition, 17, 435-443.

Chrisianson, S.-Ȧ., \& LofTus, E. F. (1987). Memory for traumatic events. Applied Cognitive Psychology, 1, 225-239.

Christianson, S.-Á., \& LofTus, E. F. (1989). Remembering emotional events: The fate of detail information. Manuscript submitted for publication.

Christianson, S.-Ȧ., Loftus, E. F., Loftus, G. R., \& Hoffman, H. (1989, November). Remembering emotional events: Differential attention versus special mechanism. Paper presented at the 30th Annual Meeting of the Psychonomic Society, Atlanta, Georgia. (Bulletin of the Psychonomic Society, 1989, 27, 499 [Abstract No. 140].)

Clifford, B. R., \& Hollin, C. (1981). Effects of type of incident and the number of perpetrators on eyewitness memory. Journal of Applied Psychology, 66, 364-370.

Clifford, B. R., \& ScotT, J. (1978). Individual and situational factors in eyewitness testimony. Journal of Applied Psychology, 63, 352-359.
Heuer, F. (1987). Remembering detail: The role of emotion in longterm memory. Unpublished doctoral dissertation, New School for Social Research, New York.

LofTUS, E. F., \& BURNS, T. E. (1982). Mental shock can produce retrograde amnesia. Memory \& Cognition, 10, 318-323.

Reisberg, D., Heuer, F., McLean, J., \& O'Shaugnessy, M. (1988). The quantity, not the quality, of affect predicts memory vividness. Bulletin of the Psychonomic Society, 26, 100-103.

Rubin, D. C., \& Kozin, M. (1984). Vivid memories. Cognition, 16, 81-95.

WinOGRAD, E., \& Killinger, W. A., JR. (1983). Relating age at encoding in early childhood to adult recall: Development of flashbulb memories. Journal of Experimental Psychology: General, 112, 413-422.

Yuille, J. C., \& Cutshall, J. L. (1989). Analysis of the statements of victims, witnesses, and suspects. In J. C. Yuille (Ed.), Credibility assessment. Dordrecht, The Netherlands: Kluwer.

\section{NOTES}

1. This finding highlights the difficulty that exists with defining centrality in real-life memories. Laboratory studies, however, have an advantage over autobiographical studies of this type because normative data can be used to assist in the definition of centrality of detail.

2. Also challenging the rehearsal explanation is the finding of Rubin and Kozin (1984) that many personal flashbulb memories were not reported as being rehearsed very often.

(Manuscript received August 29, 1989.) 